of one value of $A$ and nonreinforcing that response in the presence of another value of $A$, while holding the value of $B$ constant. Then the same response can be placed under the differential control of two values of $B$ while the value of $A$ is held constant. If these operations are successful, a compound stimulus composed of two elementary stimuli has been identified. To demonstrate that these two elemental stimuli, A and B, can enter into a configural association, one must now show that the subject can respond differentially to the compound stimulus $\mathrm{AB}$ and its elements. This can be done by demonstrating that the subject can learn one response, $R 1$, in the presence of $A B$, and a different response, $R 2$, in the presence of the A and B elements, where R1 and R2 are incompatible.

(Manuscript received June 24, 1988: revision accepted for publication December 28, 1988.)

\title{
The Mesolimbic Dopamine System: From Motivation to Action An International Workshop Malta
} September 25-29, 1989

An international workshop on the Mesolimbic Dopamine System (From Motivation to Action) will be held, under the auspices of the European Behavioural Pharmacology Society, in Malta during the week of September 25-29, 1989.

Participating invited speakers include Ahlenius, Beninger, Bozarth, Buchsbaum, Carlsson, Cools, Cooper, Di Chiara, Fibiger, Goldman-Rakic, Groenewegen, Koob, LeMoal, Mogenson, Nielsen, Phillips, Post, Robbins, Sahakian, Scheel-Krüger, Stinus, White, Willner, and Zacharko.

The invited lectures on Day 1 will be devoted to the behavioral pharmacology of mesolimbic dopamine; on Day 2, to the structure and function of the mesolimbic system; and, on Day 3, to mesolimbic dysfunction.

Posters are invited on any topic structurally or functionally related to mesolimbic dopamine.

For further information, please contact Professor P. Willner, Psychology Department, City of London Polytechnic, Old Castle Street, London E1 7NT, U.K. 